\title{
PERANCANGAN SISTEM INFORMASI MANAJEMEN SURAT MASUK DAN SURAT KELUAR PADA UNIVERSITAS AL AMIN MUHAMMADIYAH SORONG
}

\author{
Rendra Soekarta \\ Dosen Fakultas Teknik Universitas Al-Amin Muhammadiyah Sorong
}

\begin{abstract}
Abstrak
Perkembangan sangat menentukan adanya perubahan cara kerja serta cara menjalankan suatu pekerjaan, hal ini dapat menunjang dengan adanya sistem informasi komputer pada masa sekarang ini, Jumlah data surat yang masuk dan keluar semakin banyak dibagian administrasi umum di Universitas Al Amin Muhammdiyah Sorong, sehingga pencarian data akan menjadi tidak efisien waktu dan tenaga dengan menggunakan system pencatatan manual. Sehingga saat ini diperlukan suatu sistem manajemen surat yang lebih efektif agar dapat mempercepat pencarian data, keraja dari system tersebut dapat melakukan pencarian berdasar asal surat atau tanggal surat, dapat mencetak laporan berdasarkan hasil pencarian yang telah dilakukan berdasarkan asal surat atau tanggal surat.
\end{abstract}

Kata kunci : administrasi surat, sistem informasi

\section{Pendahuluan}

Sejalan dengan semakin lancarnya arus informasi dari segala bidang pada era informasi saat ini, peranan sarana komputer sangatlah diperlukan sebagai sarana yang digunakan oleh setiap pemakai dalam bentuk perorangan maupun dalam sebuah perusahan yang membutuhkan informasi dengan mudah dan cepat untuk memenuhi kebutuhan, salah satu permasalahan utama adalah bagaimana mengolah data sedemikian rupa untuk menghasilkan informasi yang tepat cepat dan akurat, dan mudah digunakan oleh pengguna informasi. Sistem manajemen administrasi surat yang ada masih manual, oleh karena itu pembuatan aplikasi ini sangat dibutuhkan. Dengan banyaknya jumlah surat yang dibuat dan diterima, maka pencarian data akan menjadi tidak efisien waktu dan tenaga. Sehingga pada saat ini diperlukan suatu sistem manajemen administrasi surat yang lebih terstruktur agar dapat mempercepat pembuatan pelaporan dan pencarian data yang ada.

\section{Perumusan dan Batasan Masalah}

Dari uraian latar belakang masalah diatas, maka dapat dirumuskan bahwa masalah yang melatar belakangi penelitian ini adalah kurang efisiennya pencarian data surat masuk dan surat keluar, serta bagaimana membuat sistem administrasi manajemen surat Yang cepat dan tepat.

Sedangkan batasan permasalahan yang dibahas hanya dibatasi pada permasalahanpermasalahan sebagai berikut :

- Pembuatan sistem aplikasi menggunakan VisualFoxpro 9.0

- Pengarsipan Surat Masuk

- Pengarsipan Surat Keluar

\section{Tujuan Penelitian}

Tujuan penelitian ini adalah membuat suatu sistem administrasi manajemen surat pada bidang suratmenyurat sehingga dapat membantu pegawai tata usaha untuk lebih mudah dan cepat dalam bekerja terutama dalam hal penanganan masalah administrasi surat.

\section{Tinjauan Pustaka}

Selama ini proses administrasi suratmenyurat masih di data dengan cara manual. Proses yang dilakukan selama ini hanya memisahkan proses suratmenyurat menjadi dua, yaitu surat 
masuk dan surat keluar. Semua proses keluar masuk surat dicatat dalam sebuah buku besar. Proses surat masuk dibagi menjadi dua, yaitu surat pribadi dan surat dinas. Surat pribadi akan langsung disampaikan kepada pemiliknya. Sedangkan surat dinas akan diperiksa oleh bagian tata usaha. Setelah itu, maka surat akan diteruskan untuk kemudian diberi disposisi. Untuk Surat keluar setelah diparaf oleh bagian yang berwenang dan ditandatangani, akan dicatat dalam buku besar kemudian surat dapat dikirimkan.

Hal ini tidak menutup kemungkinan akan hilangnya beberapa buah surat. Hal ini juga akan menghambat usaha pencarian sebuah data. Dalam proses pemberian surat tugas, dilakukan penghitungan jumlah surat tugas untuk masing-masing personal. Untuk mengatasi hal tersebut, dibuatlah sebuah sistem administrasi manajemen surat dengan menggunakan bahasa pemrograman Visual Foxpro 9.0

\section{Metodologi Penelitian}

Metode penelitian yang dilakukan dalam proses penelitian ini adalah:

a. Studi Literatur

Mempelajari proses surat-menyurat baik surat masuk dan surat keluar. Mengumpulkan data dan mempelajari semua informasi yang akan dibutuhkan.

b. Perancangan dan Pembuatan Aplikasi Membuat desain sistem informasi manajemen surat.

c. Pengujian dan Perbaikan

Menguji aplikasi yang telah dibuat. Mencari kelemahan dari aplikasi yang telah dibuat.Memperbaiki kelemahan-kelemahan dan kesalahan dari aplikasi.

\section{Scope Of Product}

Tujuan dari pengembangan proyek program ini yaitu untuk membuat aplikasi baru yang disebut dengan Sistem Informasi Administrasi Manajemen Surat. Pengguna aplikasi ini menginginkan dapat mengarsip surat masuk dan surat keluar. Pengarsipan berdasarkan Nomor, tanggal, pengirim dan perihal untuk memudahkan pencarian surat dan pembuatan laporan surat masuk maupun surat keluar.

Aplikasi surat ini mempunyai Speisfikasi seperti di bawah ini :

1. Aplikasi kearsipan ini dijalankan pada personal komputer pada bagian bagian administrasi umum.

2. Bagian Administrasi Umum dapat mengakses aplikasi dengan memasukkan user id dan password yang benar, dapat melakukan Penginputan, Pengeditan, Membatalkan, Menghapus surat masuk dan keluar.

3. Bagian Administrasi Umum dapat mencetak laporan berdasarkan asal surat dan tanggal surat masuk dan keluar

Keuntungan dari Sistem ini :

1. Memudahkan bagian administrasi umum dalam mengarsip surat masuk dan surat keluar.

2. Mempercepat proses pencarian surat

3. Mempercepat dalam pembuatan laporan surat masuk dan keluar

\section{Perancangan Sistem}

Rancangan sistem adalah kegiatan untuk merancang suatu sistem yang dilakukan untuk menggambarkan proses berlangsungnya suatu sistem.

\subsection{Data Flow Diagram}

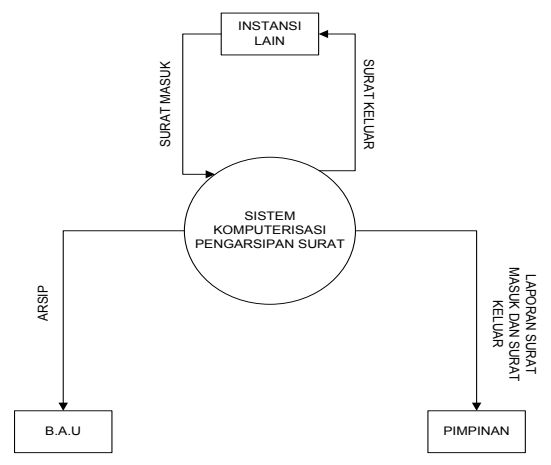

Gambar 1.Diangram Konteks 
ISSN 1979-7540

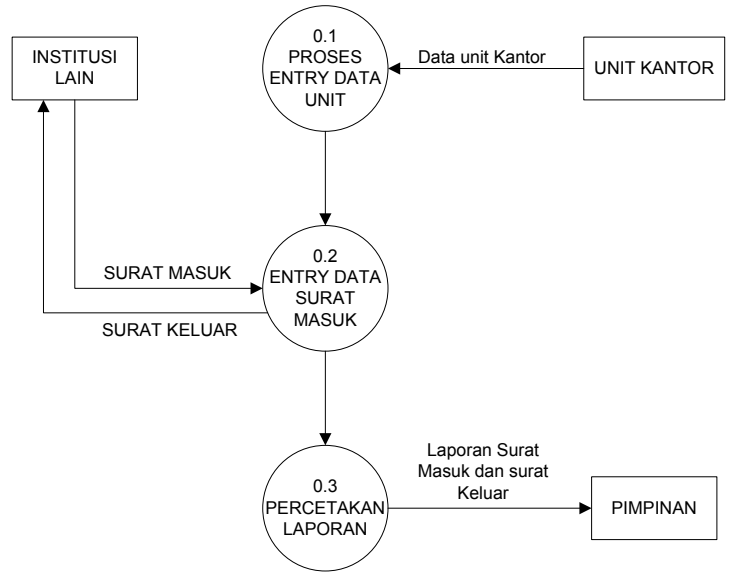

Gambar 2.DFD Level 0

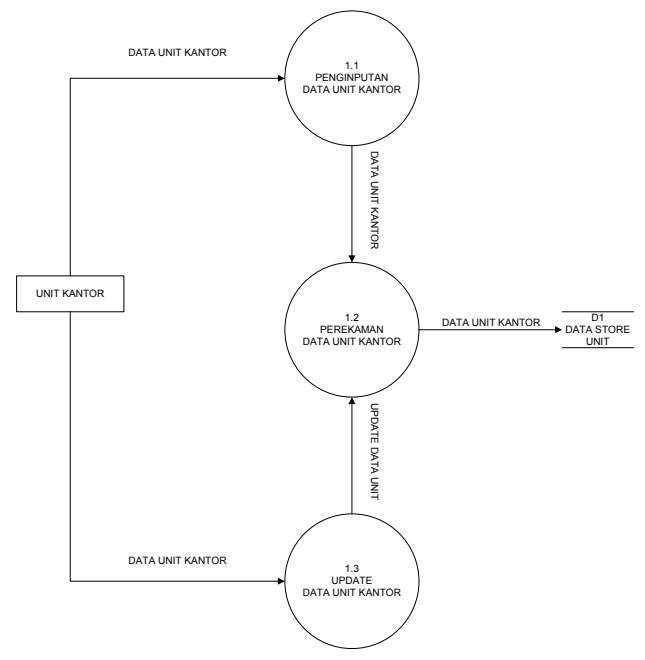

Gambar 3.DFD Level 1 Proses 1 entry data unit kantor

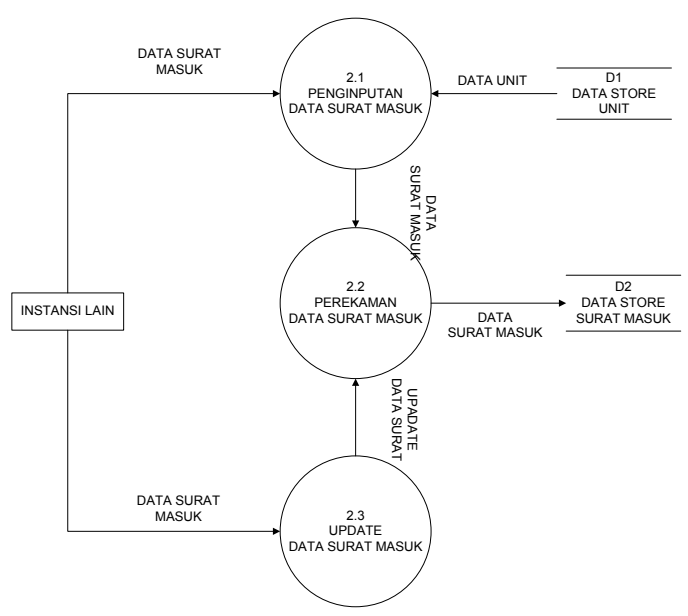

Gambar 4.DFD Level 1 proses 2 entry data surat masuk

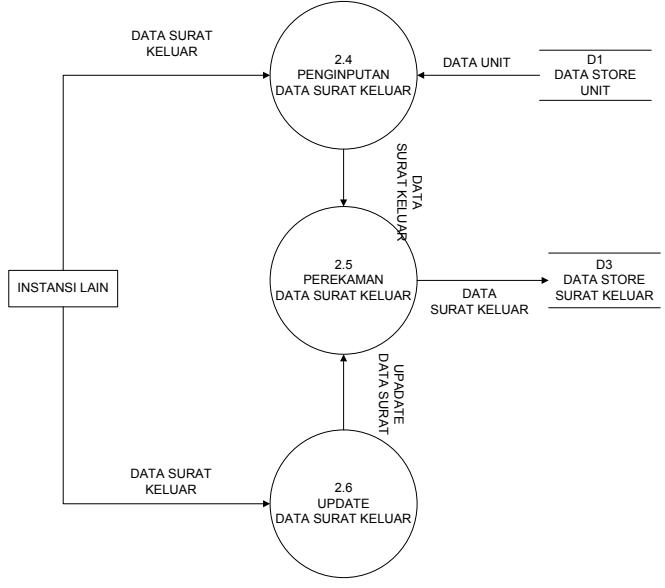

Gambar 5.DFD Level 1 proses 2 entry data surat keluar

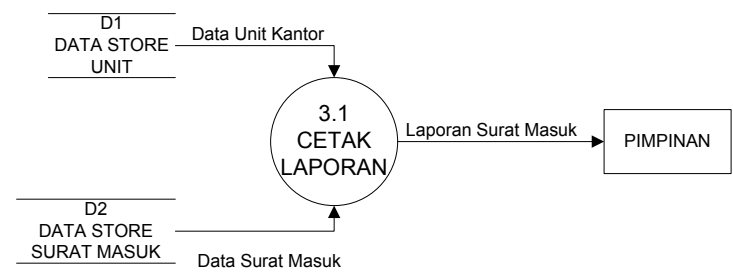

Gambar 6.DFD Level 1 proses 3 cetak surat masuk

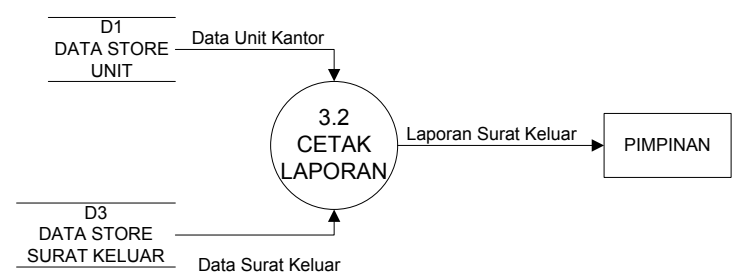

Gambar 7.DFD Level 1 proses 3 cetak surat keluar

\subsection{Kamus Data}

Kamus data adalah katalog fakta tentang data dan aliran kebutuhan kebutuhan informasi dan sistem informasi. Dengan menggunakan kamus data sistem analisis dapat mendefenisikan data yang mengalir di sistem dengan lengkap. Kamus data dibuat pada tahap analisis sistem dan digunakan baik pada tahapan analisis maupun pada tahap perancangan sistem. Biasanya dalam penggunaan kamus data memuat hal-hal sebagai berikut : 
1. Nama Aliran data

Kamus data berdasarkan aliran data yang mengalir di DFD, maka nama dari aliran data juga harus dicatat di kamus data, sehingga mereka yang membaca DFD dan memerlukan penjelasan lebih lanjut tentang suatu aliran data tertentu di DFD dapat langsung dengan mudah mencari di kamus data.

2. Aliran Data

Aliran data menunjukkan dari mana data mengalir dan kemana data akan menuju. Keterangan aliran data ini perlu dicatat di kamus data supaya dengan mudah mencari aliran data di DFD.

3. Penjelasan

Untuk lebih memperjelas lagi tentang makna dari aliran data yang dicatat di kamus data, maka bagian penjelasan dapat diisi dengan keterangan keterangan aliran data tersebut.

4. Struktur data

Dapat menggambarkan aliran data yang dicatat di kamus data terdiri dari item - item apa saja.

Kamus data dapat mencerminkan data yang jelas tentang data yang dicatatnya berdasarkan DFD yang dirancang pada halaman sebelumnya maka kamus data yang dirancang adalah Sebagai berikut :

- $\quad$ SRS Data Unit Kantor :

Nama Aliran Data:Data Unit Kantor

Keterangan: Data unit mana yang akan mengirim atau menerima surat

Dari: $\quad$ Kesatuan luar unit kantor, proses 0.1 entry data unit kantor, proses 1.1 penginputan data unit kantor, proses 1.2 perekaman data unit kantor, proses 1.3 update data unit kantor, file unit.

Ke: $\quad$ proses 0.1 entry data unit kantor, proses 0.2 entry data surat, proses 1.1 penginputan data unit kantor, proses 1.2 perekaman data unit kantor, proses 1.3 update data unit kantor, file unit.

Struktur Kodeunit, namaunit.

Data:

- $\quad$ SRS Data Surat Masuk :

Nama Aliran Data : Surat Masuk

Keterangan: Data surat-surat yang masuk.

Dari: $\quad$ Kesatuan luar instansi lain, proses 2.1 penginputan data surat masuk, proses 2.2 perekaman data surat masuk, proses 2.3 update data surat masuk, file suratmasuk.

$\mathrm{Ke}$ : $\quad$ proses 0.2 entry data surat, proses 2.1 penginputan data surat masuk, proses 2.2 perekaman data surat masuk, proses 2.3 update data surat masuk, file suratmasuk, proses 3.1 cetak laporan suratmasuk.

Struktur Nosuratm, tglsurat, tglterima, Data: dari, perihal, lampiran, kodeunit.

- $\quad$ SRS Data Surat Keluar :

Nama Aliran Data : Surat keluar

Keterangan: Data surat-surat yang keluar. Dari: $\quad$ Proses 0.2 entry data surat, proses 2.4 penginputan data surat keluar, proses 2.5 perekaman data surat keluar, proses 2.6 update data surat keluar, file suratkeluar.

Ke: $\quad$ Instans lain, proses 2.4 penginputan data surat keluar, proses 2.5 perekaman data surat keluar, proses 2.6 update data surat keluar, file suratkeluar, proses 3.2 cetak laporan surat keluar.

Struktur Nosuratk, tglsurat, tujuan, Data: $\quad$ perihal, lampiran, kodeunit.

- $\quad$ SRS Data Laporan Surat Masuk :

Nama Aliran Data : Laporan Surat masuk

Keterangan: Data laporan surat - surat yang masuk.

Dari: $\quad$ Proses $\quad 0.3$ pencetakan laporan, proses 3.1 cetak laporan surat masuk.

Ke: Pimpinan. 
ISSN 1979-7540

Struktur Nosuratk, tglsurat, tujuan, Data: perihal, lampiran, nama unit.

- SRS Data Laporan Surat Keluar :

Nama Aliran Data : Laporan Surat Keluar

Keterangan: Data laporan surat - surat yang keluar.

Dari: $\quad$ Proses $\quad 0.3$ pencetakan laporan, proses 3.2 cetak laporan surat keluar.

Ke:

Struktur Nosuratk, tglsurat, tujuan, Data:

\subsection{ERD Sistem Informasi Manajemen Surat}

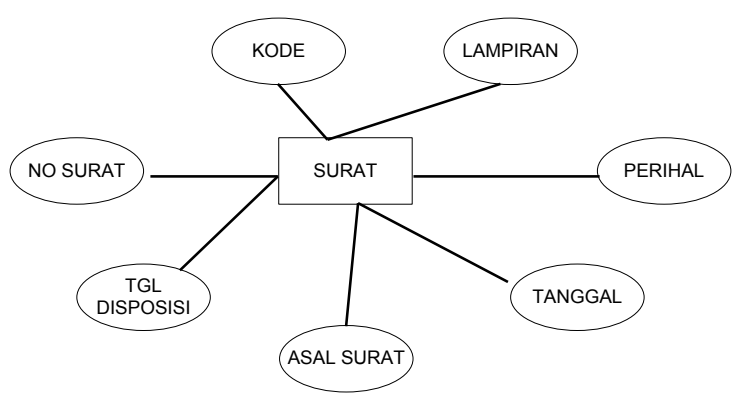

Gambar 8.ERD Surat

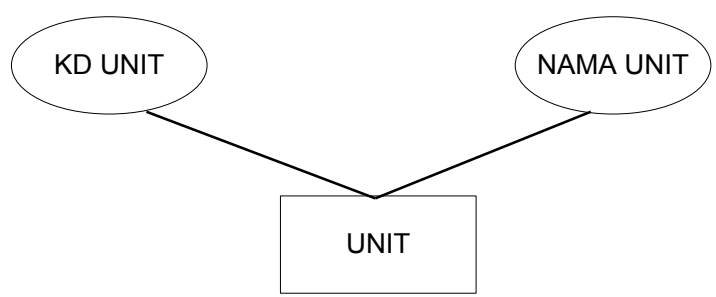

Gambar 9.ERD Unit

\subsection{Rancangan Schema Basis data}

Tabel 1. Schema Database unit.dbf

\begin{tabular}{lllll}
\hline No & $\begin{array}{l}\text { Field } \\
\text { Name }\end{array}$ & Type & Width & Keterangan \\
\hline 1. & Kodeunit & Character & 2 & Kode unit \\
\hline 2. & Namaunit & Character & 35 & Nama unit \\
\hline
\end{tabular}

Tabel 2. Schema Database surat masuk.dbf

\begin{tabular}{lllll}
\hline No & $\begin{array}{l}\text { Field } \\
\text { Name }\end{array}$ & Type & Width & Keterangan \\
\hline 1. & Nosuratm & Character & 24 & $\begin{array}{l}\text { Nomor } \\
\text { SuratMasuk }\end{array}$ \\
\hline 2. & Tglsurat & Date & 8 & $\begin{array}{l}\text { Tanggal } \\
\text { surat }\end{array}$ \\
\hline 3. & Tglterima & Date & 8 & $\begin{array}{l}\text { Tanggal } \\
\text { Terima }\end{array}$ \\
\hline 4. & Asal surat & Character & 20 & $\begin{array}{l}\text { Asal Surat } \\
\text { masuk }\end{array}$ \\
\hline 5. & Perihal & Character & 20 & Perihal \\
\hline 6. & Lampiran & Numeric & 2 & Lampiran \\
\hline 7. & Kodeunit & Character & 2 & Kodeunit \\
\hline & & & &
\end{tabular}

Tabel 3. Schema Database surat masuk.db

\begin{tabular}{lllll}
\hline No & $\begin{array}{l}\text { Field } \\
\text { Name }\end{array}$ & Type & Width & Keterangan \\
\hline 1. & Nosuratk & Character & 24 & $\begin{array}{l}\text { Nomor } \\
\text { Suratkeluar }\end{array}$ \\
\hline 2. & Tglsurat & Date & 8 & $\begin{array}{l}\text { Tanggal } \\
\text { surat }\end{array}$ \\
\hline 3. & Tujuan & Character & 30 & $\begin{array}{l}\text { Tujuan } \\
\text { Suratkeluar }\end{array}$ \\
\hline 4 & Perihal & Character & 20 & Perihal \\
\hline 5. & Lampiran & Numeric & 2 & Lampiran \\
\hline 6. & Kodeunit & Character & 2 & Kodeunit \\
\hline & & & & \\
\hline
\end{tabular}

\subsection{Relasi Basis data}

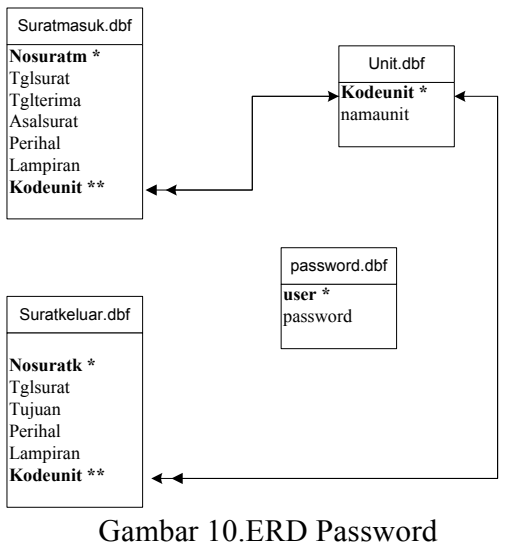

7.6 Rancangan Input Umum

Tabel 4. Rancangan Input Umum

\begin{tabular}{|c|c|c|}
\hline No & Nama Input & Keterangan \\
\hline 1 & Input Data Unit & Masukan data unit kantor. \\
\hline 2 & $\begin{array}{l}\text { Input } \\
\text { Masuk }\end{array}$ & $\begin{array}{l}\text { Masukan data-data surat } \\
\text { yang masuk. }\end{array}$ \\
\hline 3 & $\begin{array}{l}\text { Input } \\
\text { Keluar }\end{array}$ & $\begin{array}{l}\text { Masukan data-data surat } \\
\text { yang keluar ke instansi } \\
\text { lain. }\end{array}$ \\
\hline
\end{tabular}


ISSN 1979-7540

\subsection{Rancangan Output Umum}

Tabel 5. Rancangan Output Umum

\begin{tabular}{|c|c|c|c|c|c|}
\hline No & Nama 0 & it & Ketera & ngan & \\
\hline 1. & $\begin{array}{l}\text { Browse } \\
\text { Masuk }\end{array}$ & Surat & $\begin{array}{l}\text { Cetak } \\
\text { masuk }\end{array}$ & kelayar & surat \\
\hline 2. & $\begin{array}{l}\text { Browse } \\
\text { keluar }\end{array}$ & Surat & $\begin{array}{l}\text { Cetak } \\
\text { keluar }\end{array}$ & kelayar & surat \\
\hline 3. & $\begin{array}{l}\text { Laporan } \\
\text { Masuk }\end{array}$ & Surat & $\begin{array}{l}\text { Cetak } \\
\text { masuk }\end{array}$ & keprinter & surat \\
\hline 4. & $\begin{array}{l}\text { Laporan } \\
\text { Keluar }\end{array}$ & Surat & $\begin{array}{l}\text { Cetak } \\
\text { keluar }\end{array}$ & keprinter & surat \\
\hline
\end{tabular}

\subsection{Arsitektur Jaringan}

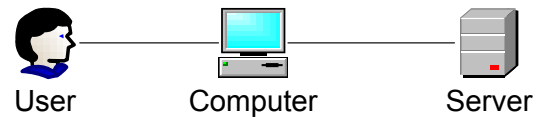

Gambar 11. Arsitektur Jaringan

\subsection{Tampilan Program}

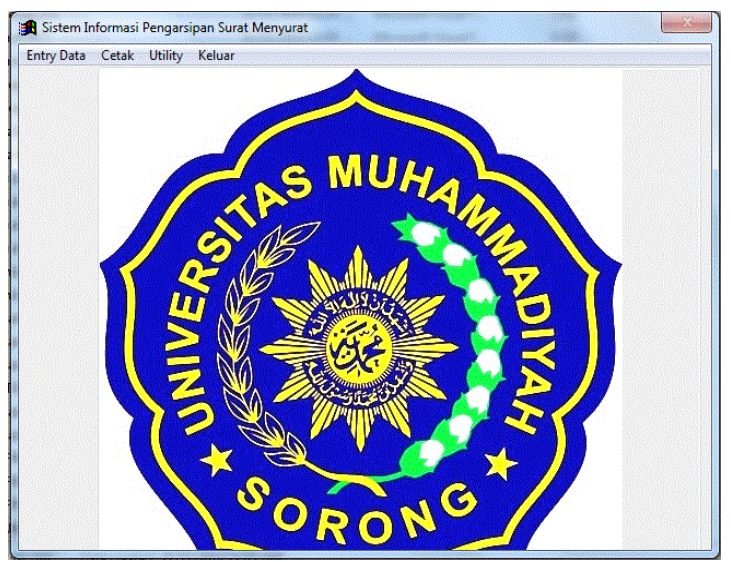

Gambar 12. Tampilan Menu utama

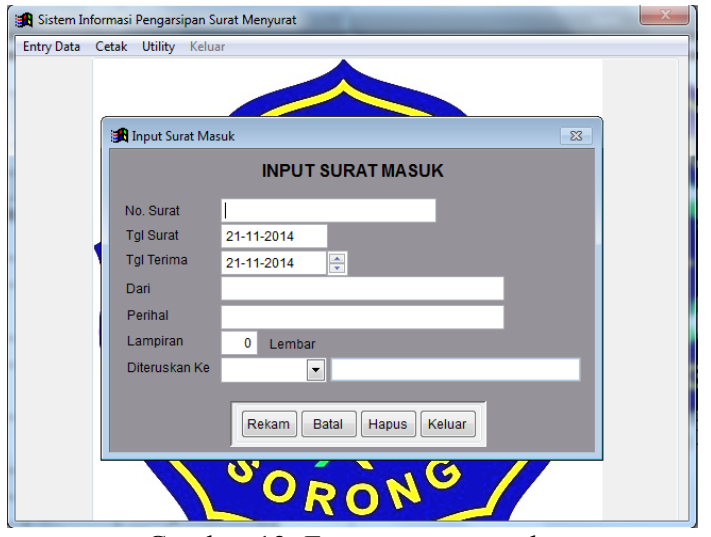

Gambar 12. Form surat masuk

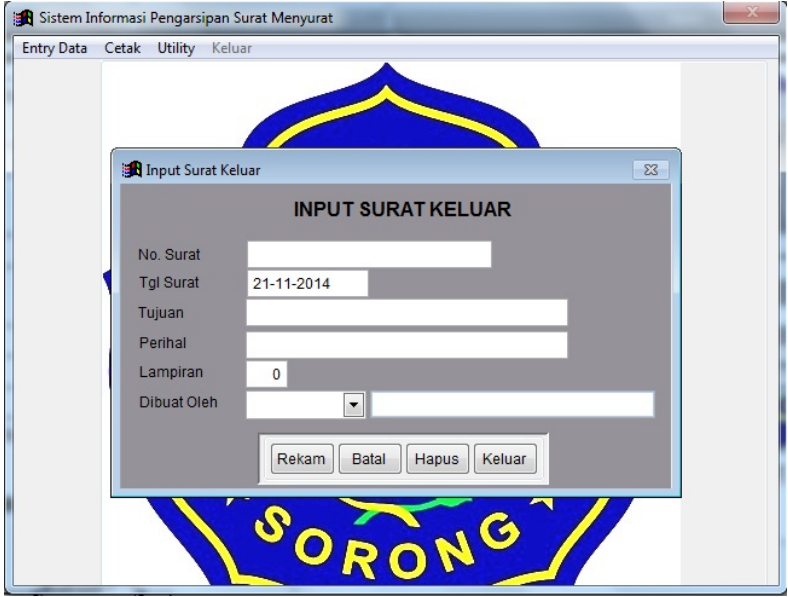

Gambar 12. Form surat masuk

\subsection{Kesimpulan}

Untuk lebih memahami yang telah dikemukakan penulis sebelumnya, maka dapat ditarik beberapa kesimpulan sebagai berikut :

Sistem komputerisasi pengarsipan surat masuk dan surat keluar pada kondisi yang sedang berjalan pada Universitas Al Amin Muhammdiyah Sorong mempunyai beberapa kelemahan sebagai berikut :

- Pemanfaatan waktu kerja kurang efektif dan efisien dalam menghasilkan informasi khususnya surat masuk dan surat keluar.

- Pengorganisasian surat terkadang surat tersebut tidak diketahui kemana arah surat tersebut diteruskan.

Agar pemanfaatan sistem komputerisasi surat yang dibangun ini lebih ditingkatkan, maka ada beberapa saran dari penulis guna mendukung hal tersebut :

Perlu pengembangan apliksi ini yang cakupannya lebih luas lagi.

\section{DAFTAR PUSTAKA}

Herianto, Tjendri, 1997, Tuntunan Praktis Pemrograman: Visual FoxPro 5.0, Jilid I, Jakarta, PT. Elex Media Komputindo.

Herianto, Tjendri, 1997, Tuntunan Praktis Pemrograman: Visual FoxPro 5.0, Jilid II, Jakarta, PT. Elex Media Komputindo. 
Jogiyanto, H.M., 1995, Analisis dan Disain Sistem Informasi: Pendekatan terstruktur,Yogyakarta, Andi Offset.

Kadir Abdul, Pemrograman Basis Data Dengan Visual Fox Pro 5, Jilid ke I, Yogyakarta, Andi Offset.

Maulana, M.N, 1996, Administrasi kearsipan, Cetakan Keempat, Jakarta, PT. Batara Niaga Media.

Oemar hamalik, 1993 ,Pengelolaan Sistem Informasi, Bandung, Trigenda Karya.

Tavri D. Mahyuzir, Analisa dan

Perancangan Sistem Pengolahan Data,

Jakarta, PT. Alex Media Komputindo. 